\title{
DETERMINATION OF THE AERODYNAMIC DRAG OF PNEUMATIC LIFE RAFTS AS A FACTOR FOR INCREASING THE RELIABILITY OF RESCUE OPERATIONS
}

\author{
Jacek Jachowski ${ }^{1}$ \\ Edyta Książkiewicz ${ }^{1}$ \\ Izabela Szwoch ${ }^{\star 2}$ \\ ${ }^{1}$ Gdynia Maritime University, Poland \\ ${ }^{2}$ Gdańsk University of Technology, Poland \\ *Corresponding author: izaczeka@pg.edu.pl (I. Szwoch)
}

\begin{abstract}
Ensuring the safety of ship crews at sea is of the utmost importance. Life rafts are one of the basic components of any seagoing vessel and ensuring their stability is an important component of maritime research. This study concerns the determination of the aerodynamic drag coefficients of pneumatic life rafts in a full range of wind speed and directions. The drag coefficients are based on full-scale experimental studies and numerical calculations (computational fluid dynamics) carried out with Flow-3D software. Two types of life rafts are analysed in the numerical simulations, namely, a non-deformed raft and a raft deformed under the influence of wind pressure at a given flow velocity. The shape of the deformed pneumatic life raft is recreated on the basis of photographic documentation from experimental studies. The results of the numerical calculations are verified on the basis of full-scale flow experiments carried out at the Low Speed Wind Tunnel T-3 Laboratory at the Institute of Aviation in Warsaw. This study shows that there is a dependence of aerodynamic drag on the degree of deformation of the above-water part of the life raft, as well as the angle of the raft setting to the wind. In real water conditions, this angle depends mainly on the anchor point of the drift anchor and therefore should be considered at the design stage, which will directly reduce the wind leeway of the raft.
\end{abstract}

Keywords: : life raft, simulation of drag force, leeway, computational fluid dynamics (CFD)

\section{INTRODUCTION}

Accidents at sea have always happened and cannot be completely eliminated. When they occur, the survivors are forced to use the rescue equipment available on the ship. Pneumatic life rafts are popular among collective rescue measures. Life rafts are life-saving measures that, due to the lack of their own propulsion, drift in the sea until found by rescue services. The drift of the raft is determined by environmental factors and leeway, which are considered when planning a rescue operation and determining the search area. In order to quickly organise a rescue operation, search and rescue (SAR) services use available computer applications (e.g., SARMAP) to correctly designate the search area. These applications are based on input data, including the leeway characteristics of a floating object.

In the case of a pneumatic life raft, it is difficult to correctly predict and take leeway into account, because the raft tent is deformed by wind pressure. The variable windage area makes it difficult to determine the certain position of the object of interest and thus to determine the search area. The study considers the calculation of the aerodynamic drag of pneumatic life rafts as a component of leeway, demonstrating the dependence of this drag on the degree of deformation of the above-water part of the life rafts. The results of the calculations are compared with the results of experiments carried out in a wind tunnel, which confirm their reliability and make it possible to draw appropriate conclusions. 


\section{THEORETICAL BACKGROUND}

In order to correctly determine the search area for a drifting life raft, it is necessary to consider the leeway of the search object [5]. Many publications on this subject have been published. The Norwegian Meteorological Institute conducted studies on drifting objects in order to define a narrow search area for the Norwegian Search and Rescue Service based on available wind information and current data [20]. The research did not consider the deformability of the drifting objects and its influence on the search area. Modelling a deformable object with a computer program is very difficult and is the subject of ongoing research [21].

Contemporary attempts to model the thermal environment of confined spaces by TENSIL MEMBRANE STRUCTURES (TMS) have been compiled in the publication Environmental Behaviour of Tensile Membrane Structures [22]. This publication indicates the lack of appropriate tools to study their internal environment and the need for further research in this area. The problem of the leeway of pneumatic life rafts has not yet been thoroughly investigated due to the difficulties in modelling deformable bodies in numerical simulations. A comprehensive approach to the problem of leeway and the factors that cause it may translate into a narrowing of the search area and an increase in the effectiveness of rescue operations.

\section{DATUM POSITION OF OBJECT AND LEEWAY}

Before commencing a search and rescue operation at sea, the most probable reference position of the object being searched for should be determined. Without the proper calculation of the basic drift and the associated uncertainty, it is difficult to predict the total drift and reduce the dimensions of the search area [8]. Difficulties are the result of large discrepancies between the direction of the life raft leeway and the direction of the wind pressure.

These discrepancies are confirmed by studies carried out in the southern Baltic by the Gdynia Maritime University in 1996-1997. The deviations between the direction of the leeway and the wind, during the $3-\mathrm{h}$ research study, oscillated from $-9^{\circ}$ to $+21^{\circ}[4]$.

The described tests carried out on life rafts showed large deviations between the leeway and the wind direction, i.e., between the components determining the drift of the object. The reference position can be determined by moving from the event site or computed reference position, the drift distance in the drift direction and plotting the resulting position on the appropriate graph [11].

The starting search point is always the datum position, which is determined based on drift and the related uncertainty. Forecasting the drift and the search area is difficult and requires continuous research and a comprehensive approach to both it and its components [3].

Leeway is the movement of an object through water caused by winds against exposed surfaces. Therefore, leeway is crucial when determining the drift and the reference position. Leeway is caused by the force of the wind pressure acting on the abovewater part of the drift object $\left(F_{X}\right)$ and the force of hydrodynamic drag acting on the underwater part of the raft $\left(F_{0}\right)$ as shown in Fig. 1 [9].

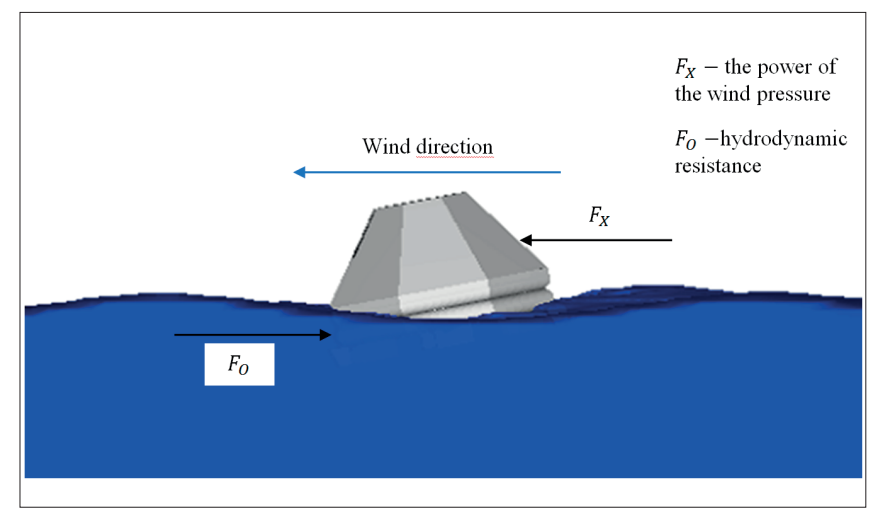

Fig. 1. Forces causing leeway (source: current study, print screen of simulation)

Given the fact that the leeway is really a movement caused by wind, model wind pressure forces acting on the abovewater portion of the drifting object should be considered. The assessment of the impact of wind pressure on the leeway is unfortunately very difficult because of the variable shape of the flexible raft structure determines the variable windage area, on which the value of the thrust force directly depends $[6,14-17]$.

\section{TUNNEL AERODYNAMIC TEST OF A PNEUMATIC LIFE RAFT}

The aerodynamic tests of the pneumatic life rafts were carried out in August 2000 at the T-3 Low Velocity Tunnel of the Institute of Aviation in Warsaw. The low-velocity wind tunnel is a closed-loop tunnel with an open measuring space that is $5 \mathrm{~m}$ in diameter and $6.5 \mathrm{~m}$ long.

The tunnel tests were carried out on three pneumatic life rafts designed for 6, 10 and 20 people, respectively, manufactured by the company "STOMIL", Grudziądz. During the tests, the rafts had the pressure of their lower buoyancy chambers reduced in order to reproduce the draft of the rafts corresponding to half the diameter of the lower chambers. The smallest life rafts had an outer diameter of $2290 \mathrm{~mm}$, a nominal height of $1190 \mathrm{~mm}$, a diameter of the lower chamber of $280 \mathrm{~mm}$ and a diameter of the upper chamber of $220 \mathrm{~mm}$.

For the 6-person life raft, the tests were carried out in a flow velocity range from 10 to $35 \mathrm{~m} / \mathrm{s}$ in the tunnel measurement space. Due to the specifications of the tests, the tests in the tunnel were carried out with a non-standard procedure, namely, a plate with 11 needles placed on it, generating an appropriate velocity, turbulence and spectrum profile in the boundary layer, was installed in the test space. The speed profile above the sea surface was mapped according to Eq. (1):

$$
\frac{V_{w}}{V_{\text {ref. }}}=\left(\frac{Z}{Z_{\text {ref. }}}\right)^{k}
$$


where:

$$
\begin{array}{ll}
V_{w} & \text { - wind speed at life raft height }(\mathrm{m} / \mathrm{s}) ; \\
V_{\text {ref. }}=V_{t .} & \text { - undisturbed flow speed }(\mathrm{m} / \mathrm{s}) ; \\
Z=h & \text { - height of life raft from water surface }(\mathrm{m}) ; \\
Z_{\text {ref. }}=1.5 & \text { - reference height }(\mathrm{m}) ; \\
k=0.11 & \text { - for the sea according to the ISO standard. }
\end{array}
$$

Knowledge regarding nonlinear processes and phenomena is essential for modelling environmental conditions during research to ensure the safety of the life raft [10]. The research carried out in the tunnel showed a large deformation of the above-water part of the life rafts. The research confirmed that the nature of the flow on the speed does not depend on the value of the wind speed in the case of a pneumatic life raft with a low aerodynamic shape. The course of the obtained force measurement results proves that the value of these forces is a function of the shape and inflow of wind [18].

\section{NUMERICAL CALCULATIONS OF DRAG FORCE OF LIFE RAFT}

The numerical computations were carried out using FLOW-3D [19] on a workstation with an Intel Xeon Gold 6244, $3.60 \mathrm{GHz}$ processor and RAM $96 \mathrm{~GB}$ volume. The geometric model of the life raft [2] used in the CFD simulations is presented in Figs. 3 and 5 and the main dimensions are given in Table 1.

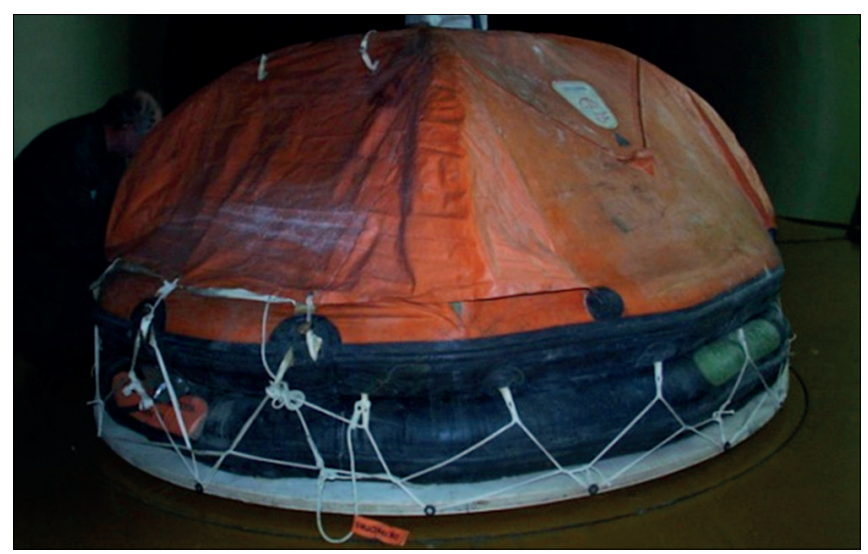

Fig. 2. Life raft during wind tunnel teste (research report, 2000)

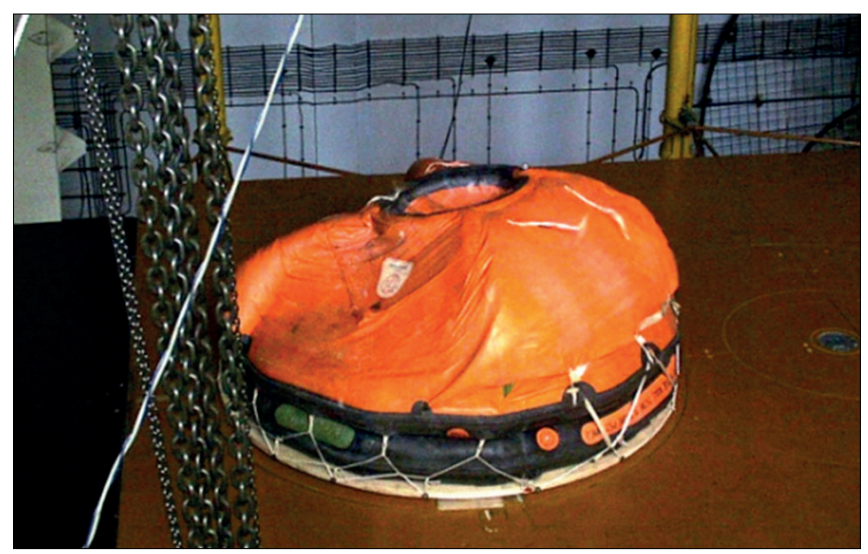

Fig. 4. Life raft during wind tunnel teste (research report, 2000)
Tab. 1. Main dimensions of life raft (research report, 2000)

\begin{tabular}{|c|c|c|c|c|}
\hline $\begin{array}{c}\text { Outer } \\
(\mathrm{m})\end{array}$ & $\begin{array}{c}\text { Height of } \\
\text { Life Raft } \\
(\mathrm{m})\end{array}$ & $\begin{array}{c}\text { Bottom } \\
\text { Tube } \\
\text { Diameter } \\
(\mathrm{m})\end{array}$ & $\begin{array}{c}\text { Top Tube } \\
\text { Diameter } \\
(\mathrm{m})\end{array}$ & $\begin{array}{c}\text { Draft } \\
\text { of Life Raft } \\
(\mathrm{m})\end{array}$ \\
\hline 2.29 & 1.19 & 0.28 & 0.22 & 0.13 \\
\hline
\end{tabular}

Two cases of life rafts were considered in the simulations, namely, non-deformed and distorted by a pressure of wind speed $V_{w}=20 \mathrm{~m} / \mathrm{s}$, as shown in Fig. 2 and 4 . On the basis of photographic documentation from experimental tests carried out in the wind tunel, the shape of a life raft deformation was reconstructed and used for the simulation.

The most important assumptions accepted in the CFD modelling of the life raft are that the full scale of the life raft in three-dimensional flow simulations is used and the life raft is treated as a rigid body [1]. The computational domain shape with the given boundary conditions is presented in Fig. 6 .

A general view of the computational mesh applied for the life raft simulations is presented in Fig. 7.

The mesh cell size and number of cells for the tested meshes are presented in Table 2 .

The calculations do not consider the dynamic deformation of the raft under the influence of wind; therefore, calculations were made for the non-deformed (Fig. 3) and deformed (Fig. 5) raft models in order to compare the results. The difference in

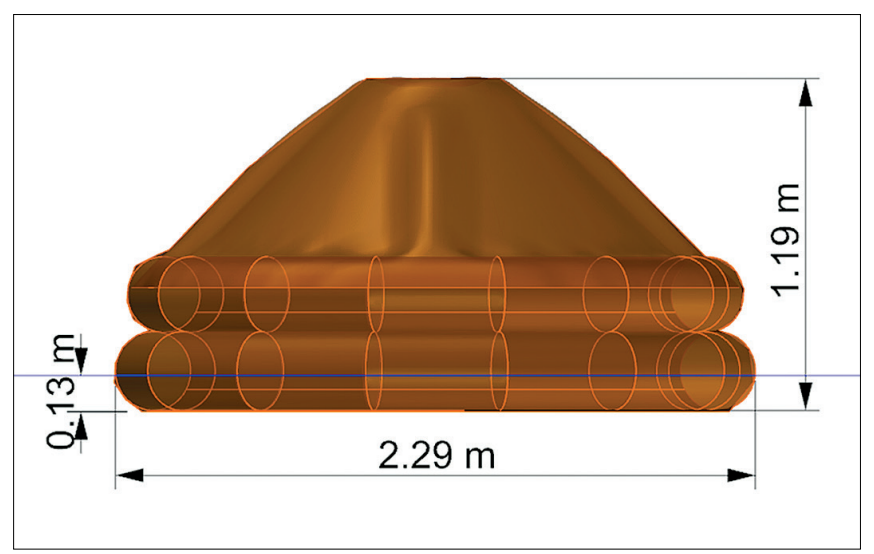

Fig. 3. Geometry and dimensions of life raft used the calculations (source: current study)

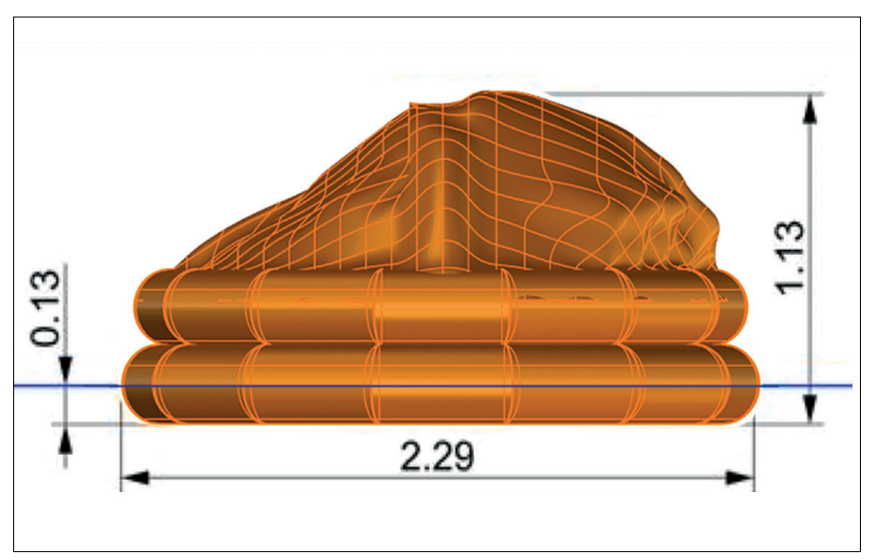

Fig. 5. Geometry and dimensions of life raft used the calculations (source: current study) 


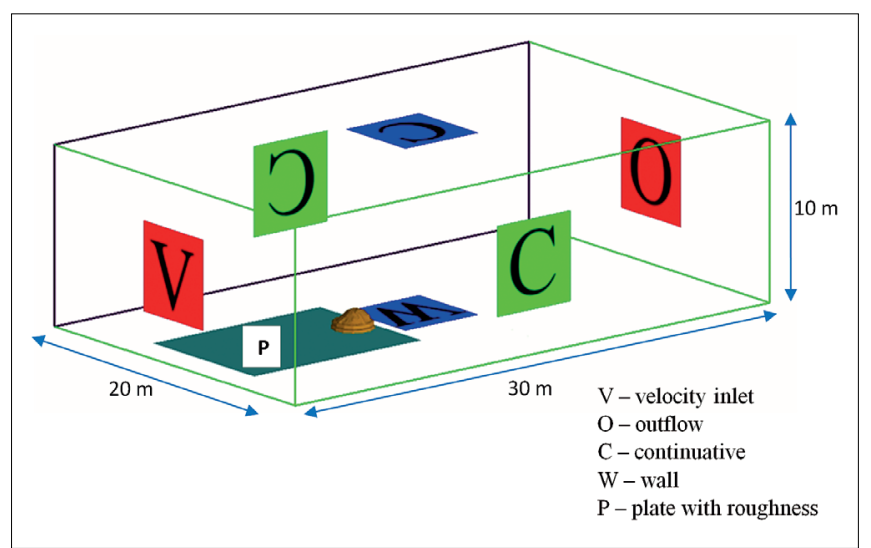

Fig. 6. Boundary conditions for computing domain of life raft with dimensions (source: current study)

Tab. 2. Mesh cell size $d$ and number of cells (source: current study)

\begin{tabular}{|c|c|c|}
\hline Mesh No. & $\mathrm{d}(\mathrm{m})$ & Number of Cells \\
\hline 1 & 0.100 & $0.60 \times 10^{6}$ \\
\hline 2 & 0.067 & $1.05 \times 10^{6}$ \\
\hline 3 & 0.050 & $1.89 \times 10^{6}$ \\
\hline
\end{tabular}

the drag coefficients was $4 \%$. As a result, the calculations were performed for the non-deformed raft geometry in the full range of the raft rotation angle from 0 to $180^{\circ}$. This approach was used due to the results of the experiment, which showed a large variability in the drag force depending on the angle of the life raft to the wind direction [7]. The simulations were made for the geometry shown in Fig. 6 for the six wind speeds considering the wind profile generated in the wind tunnel

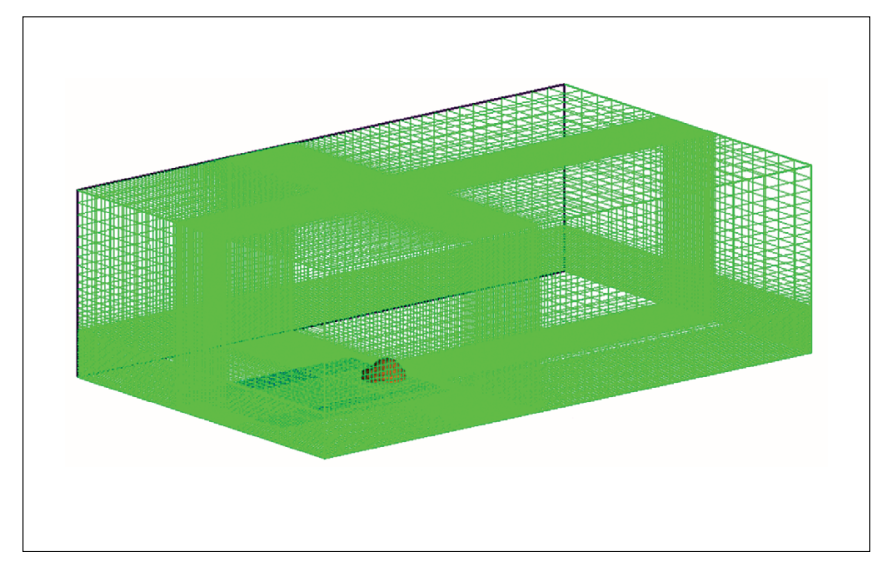

Fig. 7. Structural mesh applied for life raft simulation (source: current study)

(Eq. (1)). In the CFD simulations, the wind profile was realised by assigning a high coefficient of roughness to the plate in front of the life raft (Fig. 6).

\section{VALIDATION OF SIMULATION RESULTS}

The following assumptions were used in the CFD modelling. The computation was unsteady with an implicit pressure algorithm. The general moving object model implemented in FLOW-3D was used for modelling the rotational motion of the life raft. The rotational speed of the raft started from $0^{\circ}$ after a 5 -s simulation and achieved $180^{\circ}$ after $20 \mathrm{~s}$. In the simulation, three turbulence models were analysed in terms of turbulence closure: the standard k- $\varepsilon$ model, the k- $\omega$ twoorder model and the large vortex simulation model (LES).

In order to identify the geometry of the life raft, the turbulent mixing length was calculated using a rectangular structural mesh and the FAVOR ${ }^{\mathrm{rm}}$ technique. The mesh density was adjusted to map the shape of the geometry at the edges. The mesh size and the number of cells for the tested meshes are compared in Fig. 9. The results of the FAVOR ${ }^{\mathrm{m}}$ method, i.e., the mesh density in a block near the life raft for three mesh densities, for which a simulation was performed to examine the effect of mesh resolution on the calculation results are shown in Fig. 9. The mesh technique used in Flow 3D unfortunately has a limited spectrum of boundary layer mesh near the wall. In contrast, the FAVOR TM method does not allow for precise positioning of the walls in the cell. The disadvantage

Fig. 8. Wind profile obtained from simulation and experimental measurements for a speed of $20 \mathrm{~m} / \mathrm{s}$ (source: current study) 


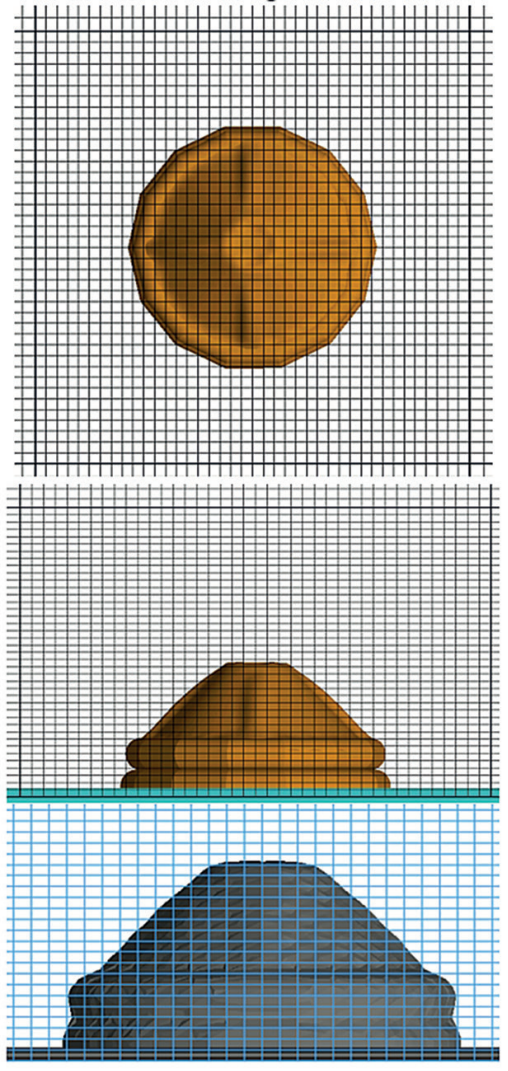

Mesh 1

Number of Cells $0.60 \times 10^{6}$
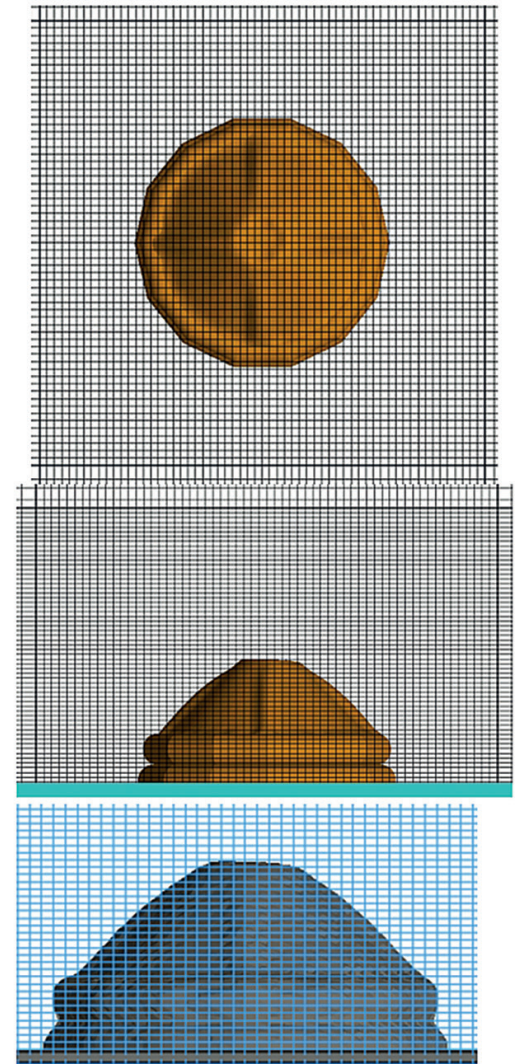

Mesh 2

Number of Cells $=1.05 \times 10^{6}$
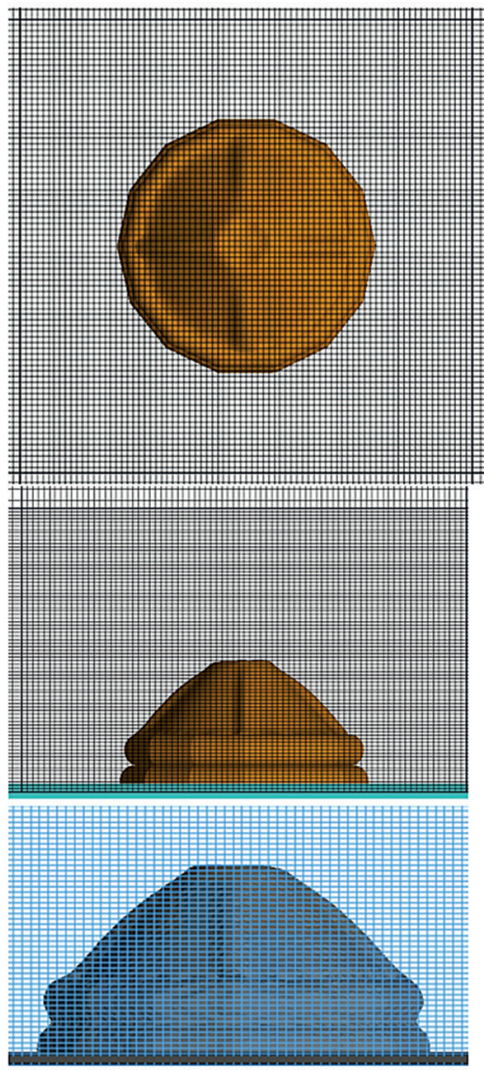

Mesh 2

Number of Cells $1.89 \times 10^{6}$

Fig. 9. Structured mesh used in FLOW-3D and the FAVOR TM technique with the original shape of thelife raft and the shape of the object after FAVOR discretisation for three mesh densities (source: current study)

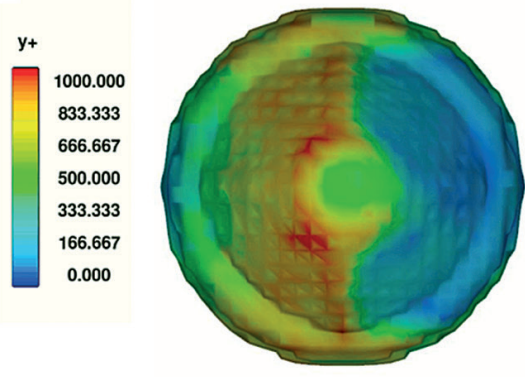

Mesh 1

Number of Cells $0.60 \times 10^{6}$

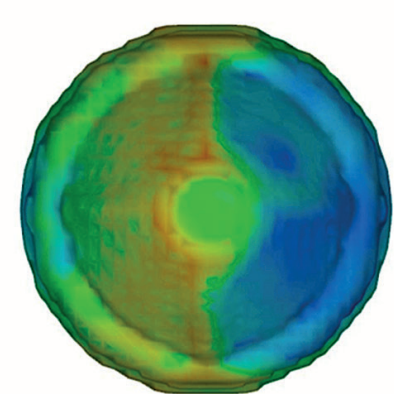

large-eddy simulation (LES)

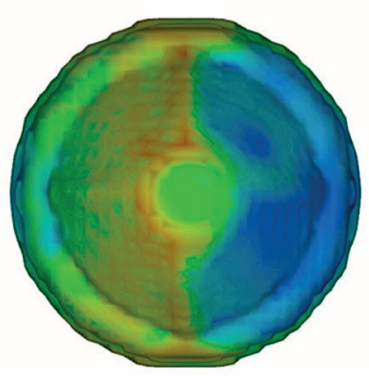

Mesh 2

Number of Cells $=1.05 \times 10^{6}$

Number of Cells $1.89 \times 10^{6}$

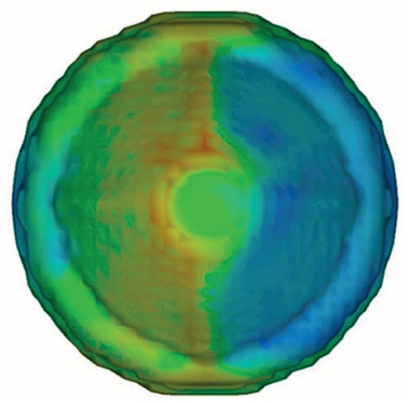

Standard k- $\varepsilon$ model

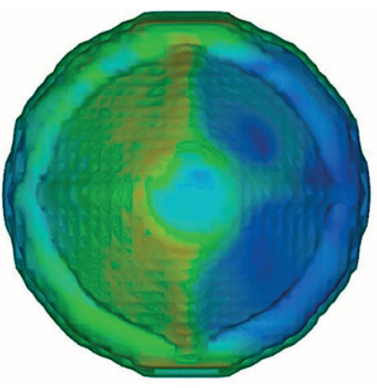

Mesh 2

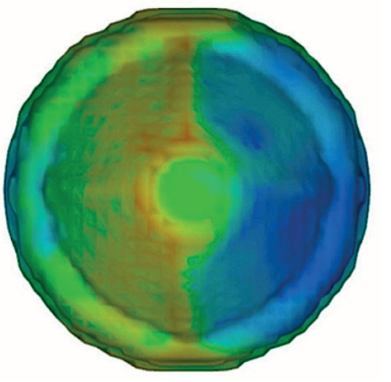

k- $\omega$ two-equation model

Mesh 2 - Number of Cells $=1.05 \times 10^{6}$

Fig. 10. Parameter $y+$ for studied turbulence models and meshes with a wind speed of $10 \mathrm{~m} / \mathrm{s}$ (source: current study) 
of this method is that it obtains a high y + value. Domain-wide structural meshing is a considerable advantage of this type of meshing. This approach reduces the problems with complex meshes when superimposing a moving object.

The $y+$ as a grid parameter as a function of cell size should be less than the value depending on the Reynolds number of flow and the thickness of the boundary layer and is greater than 30 when the inner layer smoothly transitions into the logarithmic region. The results obtained are acceptable when a parameter $\mathrm{y}+$ is less than 500 . For the tested meshes, the parameter $y+$ was determined and is shown in Fig. 10.

Although high y + values were obtained, a comparison of the results was carried out because increasing the mesh density in the entire geometry area significantly extends the computation time without changing the force values. Turbulence models were also tested with the same mesh densities. After comparing the turbulence models for Mesh 2 and mapping the shape of the life raft, the LES model was selected (Table 2). The drag force $F_{x}$ obtained from the CFD simulation using the LES model for the raft for wind speed $V_{w}=10 \mathrm{~m} / \mathrm{s}$, dependent on the mesh density, is presented in Fig. 11.

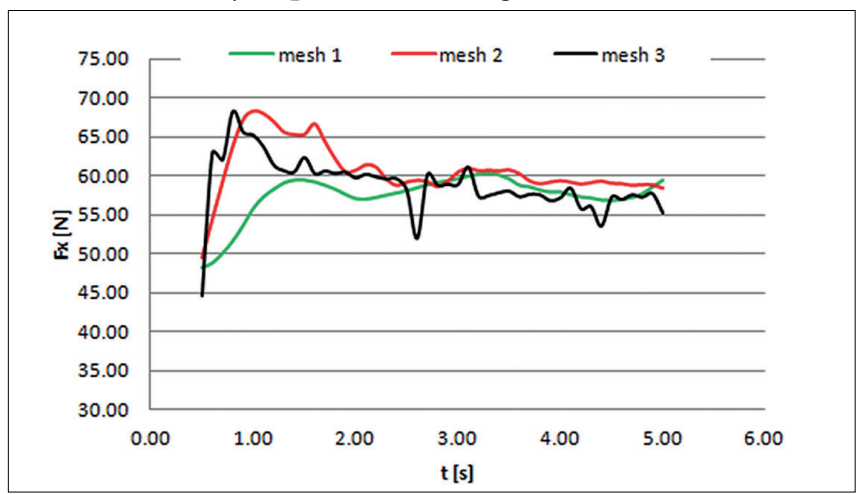

Fig. 11. Results of numerical computations with simulation time t(s) for the life raft for wind speed $V=10 \mathrm{~m} / \mathrm{s}$ using the LES model dependent on the mesh density

The relative errors $\left(\Delta F_{X}\right)$ for the life raft drag force for wind speeds $V_{w}=10$ and $20 \mathrm{~m} / \mathrm{s}$, the mesh density of $1.05 \times 106$ (Mesh 2) and three selected turbulence models are presented in Table 3.

Tab. 3. Influence of turbulence model on relative errors $\left(\Delta F_{X}\right)$ (source: current study)

\begin{tabular}{|c|c|c|}
\hline & $\Delta F_{X}(\%)$ for $10 \mathrm{~m} / \mathrm{s}$ & $\Delta F_{X}(\%)$ for $20 \mathrm{~m} / \mathrm{s}$ \\
\hline Standard k- $\varepsilon$ & 10 & 12 \\
\hline k- $\omega$ & 11 & 15 \\
\hline LES & 6 & 7 \\
\hline
\end{tabular}

The relative errors $\left(\Delta F_{X}\right)$ of the life raft drag force were determined from Eq. (2):

$$
\Delta F_{X}=\frac{F_{X_{-} E X P}-F_{X_{-} C F D}}{F_{X_{-} E X P}} * 100 \%
$$

where:
$\Delta F_{X}$
$F_{X-E X P}$
$F_{X-C F D}$
- relative errors of drag forces [-];
- measured drag forces and $[\mathrm{N}]$;
- computed drag [N].

The relative errors $\left(\Delta F_{X}\right)$ and time of computation in $h$ per $s$ of simulation (h/s) are presented in Table 4.

Tab. 4. Influence of mesh density on the accuracy of computations for LES model and computing time (source: current study)

\begin{tabular}{|c|c|c|c|}
\hline Mesh No. & $\begin{array}{c}\Delta F_{X}[\%] \text { for } 10 \\
\mathrm{~m} / \mathrm{s}\end{array}$ & $\begin{array}{c}\Delta F_{X}[\%] \text { for } 20 \\
\mathrm{~m} / \mathrm{s}\end{array}$ & $\begin{array}{c}\text { Computing Time } \\
(\mathrm{h} / \mathrm{s})\end{array}$ \\
\hline 1 & 7 & 9 & 0.97 \\
\hline 2 & 6 & 7 & 3.02 \\
\hline 3 & 10 & 11 & 6.70 \\
\hline
\end{tabular}

After analysing the results of the calculations and the available computing resources, the LES turbulence model and mesh 2 with $1.05 \times 10^{6}$ cells were chosen.

\section{SIMULATION RESULTS OF LIFE RAFT DRAG FORCE}

Examples of the CFD simulations carried out to determine the flow velocity field and hydrodynamic force generated by the life raft with a draft of $0.12 \mathrm{~m}$ for different current velocities are presented in Figs. 12 and 13.

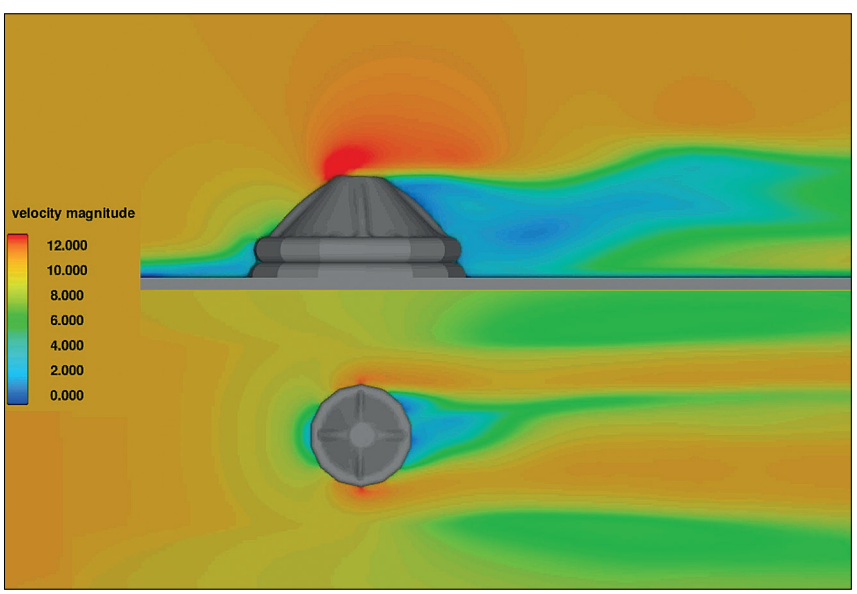

Fig. 12. Results of $3 D$ flow simulation for $V=10 \mathrm{~m} / \mathrm{s}$ : top view of velocity field and the velocity field in the horizontal plane at half-length section (source: current study, print screen of simulation)

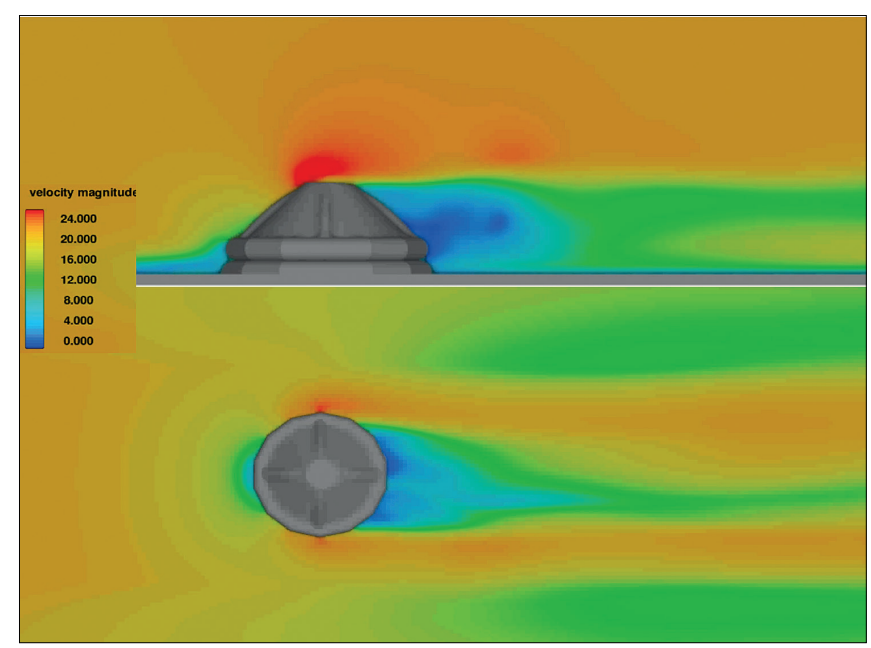

Fig. 13. Results of $3 D$ flow simulation for $V=20 \mathrm{~m} / \mathrm{s}$ : top view of velocity field and velocity field in the horizontal plane at half-length section (source: current study, print screen of simulation) 


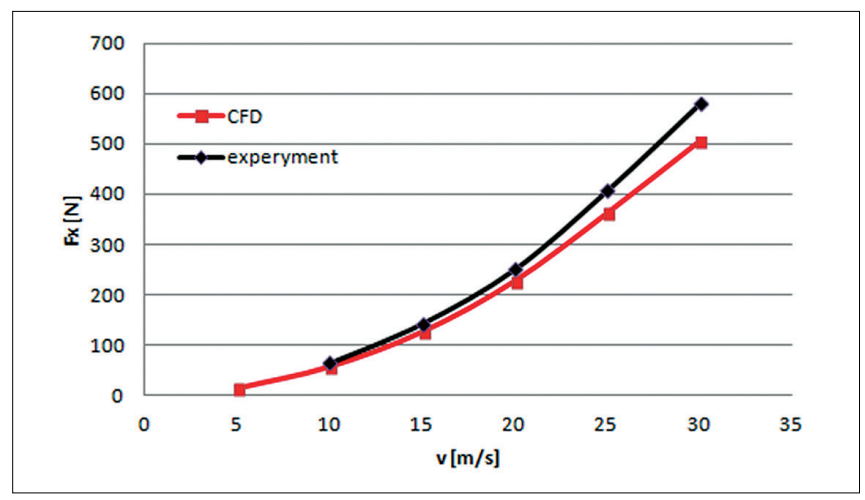

Fig. 14. Comparison of mean aerodynamic forces obtained from CFD simulation (current study) versus wind tunnel experiment for $V_{w}=20 \mathrm{~m} / \mathrm{s}$ [18]

The aerodynamic drag coefficient for different wind speeds and angles of the raft $(\alpha)$ to the wind direction was calculated according to Eq. (3):

$$
\mathrm{C}_{\alpha}=\frac{2 * F_{\alpha}}{A * \rho * V_{w}}
$$

where:

$F_{\alpha} \quad-$ drag force for the relative wind angle $(\alpha)$ ranging from $0^{\circ}$ to $180^{\circ}[\mathrm{N}]$;

$\alpha \quad-$ relative wind angle $\left(^{\circ}\right)$;

A $\quad$ - windage projected area $\left.\mathrm{m}^{2}\right)$;

$\rho \quad-$ air density $\rho=1,233\left[\frac{\mathrm{kg}}{\mathrm{m}^{3}}\right] ;$

$V_{w} \quad-$ wind speed $(\mathrm{m} / \mathrm{s})$.
Figures 12 and 13 show significant fluctuations in the velocity field behind the raft. The results of the simulation and the experiment showed a significant variation of the raft drag coefficient $C_{\alpha}$ on the relative wind angle $(\alpha)$ ranging from $0^{\circ}$ to $180^{\circ}$ (Fig. 15). The drag coefficients obtained from the CFD simulations show less variability. This effect arises from the calculations made for the non-deformable raft. The averaged drag coefficient for the raft obtained during the experiment was $C_{\alpha}=0.60$ and for the CFD simulation was $C_{\alpha}=0.56$.

\section{DISCUSSION AND CONCLUSION}

This article has compared the results of laboratory tests carried out at the Institute of Aviation in Warsaw with simulations using CFD. The results obtained from the CFD simulations were on average $7 \%$ lower than those obtained during model tests in the wind tunnel. The discrepancies in the results were probably due to smaller deformations of the life raft in the simulation than during the experiment. The main conclusions are as follows:

- Deformations of the tent of the tested raft using CFD simulation change the aerodynamic resistance up to $4 \%$;

- The angle of the raft to the wind significantly influences the drag coefficients, which ranged from 0.39 to 0.75 for the experiment and 0.48 to 0.64 for the CFD calculations.

The most important conclusions from the results of studies is a direct dependence of aerodynamic drag (and leeway) from

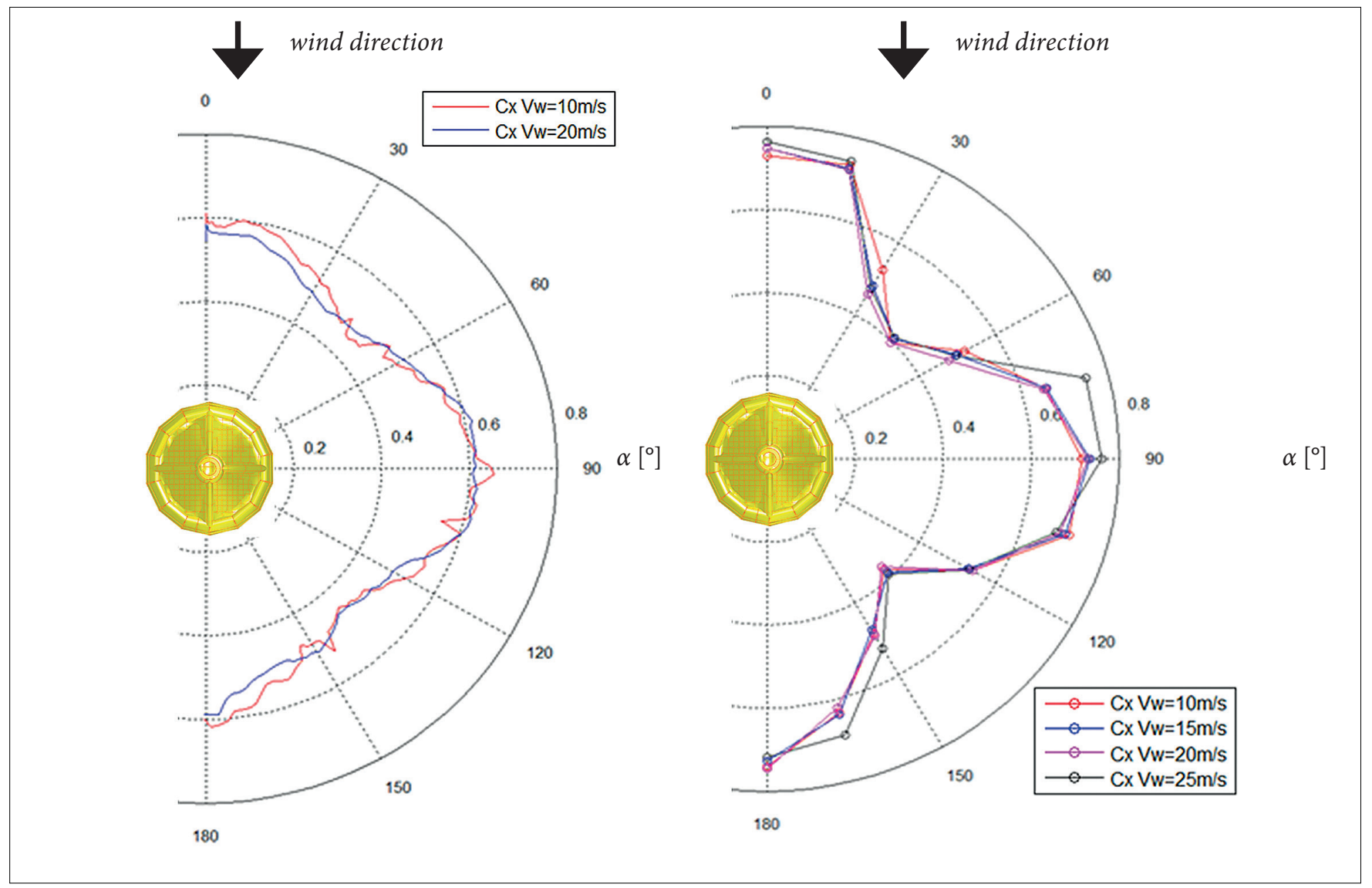

Fig. 15. Raft aerodynamic drag coefficient $\left(C_{\alpha}\right)$ for various wind velocities and relative wind angle $(\alpha)$ : CFD results (left) and experimental results [18] 
the angle to the wind raft. This angle mainly determines the drift application point, therefore, at the design stage, it should be considered, which will directly reduce the leeway of the raft.

\section{ACKNOWLEDGEMENTS}

This research was financed by Gdynia Maritime University Grant No. WN/PZ/2021/03.

\section{REFERENCES}

1. Abramowicz-Gerigk T., Burciu Z., Jachowski J., Kornacka E., Wawrzusiszyn M., 'Experimental and numerical investigation of towing resistance of the innovative pneumatic life raft', Polish Maritime Research. Vol. 24, p. 40-47, 2017. doi: 10.1515/pomr-2017-0048.

2. Abramowicz-Gerigk T., Burciu Z., Kornacka E., Jachowski J., Stefurak W., 'Innovative Life raft', TransNav - The International Journal on Marine Navigation and Safety of Sea Transportation. Vol. 9, 2015. doi: 10.12716/1001.09.04.15.

3. Burciu Z., 'Method of determining search areas in a rescue operation at sea' (in Polish), Doctoral Dissertation, Naval Academy, Gdynia, 1997.

4. Burciu Z., 'Modeling of search areas in terms of the safety of human transport at sea' (in Polish), Printing House of Warsaw University of Technology, Warsaw, 2003.

5. Burciu Z., 'Reliability of SAR action in maritime transport' (in Polish), Printing House of Warsaw University of Technology, Warsaw, 2012.

6. Burciu Z., Grabski Fr., 'The experimental and theoretical study on the reliability of the life rafts', Reliability Engineering and System Safety. Vol. 96, 2011. doi: 10.1016/j.ress.2011.06.001.

7. Bramer L., 'Methods for modeling and forecasting wind characteristics", Digital Repository, A dissertation submitted to the graduate faculty in partial fulfilment of the requirements for the degree of Doctor of Philosophy, Iowa State University, 2013.

8. Breivik Ø., Allen A., Maisondieu Ch., Olagnon M., 'Advances in search and rescue at sea', Ocean Dynamics. Vol. 63, p. 83-88, 2013. doi: 10.1007/s10236-012-0581-1.

9. Breivik Ø., Allen A. A., Maisondieu Ch., Roth J. Ch., 'Windinduced drift of objects at sea: the leeway field method', Appl Ocean Res. p. 100-109, 2011. doi: 10.1016/j.apor.2011.01.005.

10. Drzewiecki M., Sulisz W., 'Generation and Propagation of Nonlinear Waves in a Towing Tank', Polish Maritime Research. Vol. 26, 2019. doi: 10.2478/pomr-2019-0014.
11. IAMSAR, Manual, International Aeronautical and Maritime Search and Rescue Manual, Volume III, Mobile Facilities, 2005 Edition.

12. Kula K. S., 'Automatic Control of Ship Motion Conducting Search in Open Waters', Polish Maritime Research. Vol. 27, 2020. doi: 10.2478/pomr-2020-0076.

13. Małyszko M., 'Assessment of the Potential Effectiveness of the WIG Craft in Search Action at Sea Using SARMAP Software', TransNav - the International Journal on Marine Navigation and Safety of Sea Transportation, vol. 13, no. 2, 2019. doi: 10.12716/1001.13.02.23

14. Marchenko A. V., 'The floating behaviour of a small body acted upon by a surface wave' Journal of Applied Mathematics and Mechanics. Vol. 63, no. 3, p. 471-478, 1999. doi: 10.1016/ S0021-8928(99)00059-3.

15. Power J., Simones- Re A., Kennedy E., Kuczora A., Akinturk A., Veitch B., Mackinnon N S., Brown R., Boone J., 'Life raft performance in wind and waves: an experimental evaluation', RINA, Royal Institution of Naval Architects International Conference - Design and Operation of Passenger Ships Papers (2007).

16. Raman-Nair W., Power J., Simones- Re A., 'Towing dynamics of a life raft and fast rescue craft in a Surface wave', Ocean Engineering, vol. 35, 2008, doi: 10.1016/j. oceaneng.2008.03.009.

17. Raman-Nair W., Power J., Simones- Re A., Millan J., 'Numerical Model of Towing Dynamics of a Long Flexible Life Raft in Irregular Waves', Marine Technology and SNAME News, vol. 46, no. 04, doi: 10.5957/mtsn.2009.46.4.213.

18. Research report, 'Aerodynamic testing of pneumatic life rafts in the wind tunnel $\varnothing 5 \mathrm{~m}$ ' (in Polish), Report nr 168/ BA/2000/D Institute of Aviation, Warsaw 2000.

19. FLOW-3D. Available online: https://www.flow3d.com/ (accessed on 15 April 2021).

20. Breivik Ø. \& Roang K., Stochastic Forecasting of Drifting Ships and Smaller Objects, http://www.ifremer.fr/sar-drift/ public- repository / pres-leeway.pdf, (accessed 20 May 2021).

21. Heilig A., Tensile Membrane Structures and CFD Wind Load Simulation, https://www.dlubal.com/en/support-andlearning/learning/webinars/001884, (accessed 24 June 2021).

22. ElNokaly A., Chilton J. and Wilson R., Environmental Behaviour of Tensile Membrane Structures, http://eprints. lincoln.ac.uk/id/eprint/8520/1/Egypts\%20Paperm\%20final. pdf, (accessed 15 May 2021). 
CONTACT WITH THE AUTHORS

Jacek Jachowski

e-mail:j.jachowski@wn.umg.edu.pl

Gdynia Maritime University

Al. Jana Pawła II 3, 81-345 Gdynia

Poland

Edyta Książkiewicz

e-mail: e.ksiazkiewicz@wn.umg.edu.pl

Gdynia Maritime University

Al. Jana Pawła II 3, 81-345 Gdynia

Poland

Izabela Szwoch

e-mail: izaczeka@pg.edu.pl

Gdańsk University of Technology

11/12 Gabriela Narutowicza, 80-233 Gdańsk

Poland 